\title{
O ESPAÇO DA VIDA [LEBENSRAUM]: UM ESTUDO BIOGEOGRÁFICO (PARTE III)*
}

\section{FRIEDRICH RATZEL}

\section{A LUTA POR ESPAÇO}

Entre o movimento da vida, que nunca repousa, e o espaço da Terra, que não se transforma, reside uma contradição. É dessa contradição que nasce a luta por espaço. A vida se submeteu rapidamente ao solo da Terra, mas assim que esbarrou em seus limites ela refluiu, e desde então, por toda parte e sem descanso, sobre a Terra inteira, vida luta com vida pelo espaço. A expressão - muito mal-empregada e mais ainda mal compreendida - "luta pela existência" [Kampf ums Dasein] significa, na verdade, em primeiro lugar luta por espaço. Pois espaço é a primeira de todas as condições de vida e no espaço se mensura a medida de outras condições de vida, sobretudo a alimentação. Na luta pela existência é destinado ao espaço um significado semelhante àqueles pontos máximos decisivos das lutas dos povos que designamos de batalhas. Em ambos os casos, trata-se da aquisição de espaço em movimentos de avanço e recuo. $\mathrm{Na}$ medida em que aquele que é atacado tem espaço, pode esquivar-se; mas se o espaço for estreito, a luta se dá desesperadamente. Darwin partiu, no famoso terceiro capítulo de "A origem das espécies", da consideração malthusiana da [p. 52/154] relação entre a capacidade de proliferação dos organismos vivos e o espaço de vida
[Lebensraum]. Ele aceita que o homem, embora pertença aos entes que se reproduzem lentamente, em menos de 1000 anos teria preenchido a Terra por proliferação irrestrita de tal modo que não restaria mais espaço para ele. Suas reflexões não deixaram nenhuma dúvida de que sua luta pela existência deve ser em grande parte uma luta por espaço. Todavia, de maneira marcante, este lado da questão nunca foi observado de modo preciso por ele e por seus sucessores.

Um dos animais que proliferam de maneira mais lenta, o elefante, dentro de 700 a 750 anos teria 19 miIhões de descendentes, cuja longevidade contrabalançaria generosamente seu fraco aumento. Mesmo se reivindicarmos apenas a área insuficiente de 30 quilômetros quadrados por elefante, incluindo aí terras férteis e inférteis, então, nesse curto espaço de tempo, o mundo estaria superpovoado com elefantes. Com outros animais que proliferam mais rapidamente, a superpopulação teria ocorrido muito antes, e as condições de vida de cada ser deveriam se deteriorar na medida em que seu espaço de vida [Lebensraum] se tornasse mais estreito. Mas antes que os habitantes se submetam a esse estreitamento, cada um busca ampliar sua área [Gebiet] às custas de seu vizinho e a partir disso tem origem uma luta por espaço.

* Finalizando o projeto de verter para o português, direto do alemão e cotejando com a tradução para o inglês, o artigo Lebensraum: eine biogeographische Studie (1901), de Friedrich Ratzel, apresentamos o terceiro e último fragmento do texto, cuja primeira e segunda partes encontram-se publicadas nos números imediatamente anteriores desta revista. Tradução: Leonardo Arantes, professor substituto da Faculdade de Formação de Professores da UERJ; revisão técnica (cotejando com a tradução em inglês): Rogério Haesbaert, a quem o tradutor é enormemente grato. 
Então, quanto menor em natureza for uma área de morada [Wohngebiet], mais rapidamente uma forma de vida [Lebensform] fértil e móvel a ocupará completamente e, não raramente, sucederá daí o deslocamento dos organismos vivos endêmicos logo após a abertura das fronteiras. Middendorf1 define sua experiência com a extinção dos mamíferos siberianos nas palavras: "Quanto mais estreita a área de difusão, quanto maior o animal, quanto mais confiável, manso e demandado ele for, mais facilmente estará sujeito a rearranjos. A RhytinaStellleri [vaca-marinha-de-Steller] é o exemplo clássico dos processos que [p. 53/155] levaram ao recuo dos grandes mamíferos do norte da Ásia. Mas isso nos mostra apenas um lado do processo, que eu poderia chamar de o [lado] passivo: nas suas pequenas áreas costeiras, para as quais ela foi recuada no decorrer de longo espaço de tempo por razões climáticas ou outras razões que desconhecemos, ela aguarda calmamente a [sua] aniquilação. Nessa relação, seu fim assemelha-se ao de muitas plantas, em grande parte impedidas de mudar de lugar. Em contraste, muitos animais se furtam das influências hostis em virtude de sua maior mobilidade e transladam seus locais de morada [Wohnplätze]: eles se retiram.

Todavia, as migrações que acompanham os recuos não têm o mesmo significado para o organismo que os movimentos livres e irrestritos associados à disseminação [Ausbreitung]. No caso de disseminação voluntária, uma riqueza de novas condições de vida se oferece àquele [organismo], dentre as quais ele escolhe. Moritz Wagner admitiu que em muitos casos de coloração adaptativa a livre escolha de diversos animais levou à consonância com o novo local de morada [Wohnplatz], de modo que a lebre da neve, a galinha da neve e as similares variedades brancas foram originadas de forma espontânea, buscando conscientemente a paisagem nevada na qual elas se encaixavam. Em todo caso, este suposto evita a dificuldade de explicar como uma variação inicial imperceptível, desde o início já deveria ter conferido vantagem a um organismo vivo. Ao animal em recuo, por outro lado, frequentemente apenas uma determinada direção lhe está aberta, uma única saída, e comumente esta conduz a um lado menos vantajoso, de modo a acentuar a deterioração do solo, do clima, da alimentação, e ainda o efeito da limitação do espaço.

A real carência de espaço [Raumnot] nos é apresentada de maneira a mais evidente pela intrusão de ervas da-

'Alexander Theodor von Middendorff (1815-1894) foi um zoólogo e explorador russo. [N.T.I.] ninhas em um canteiro de jardim. Se nós [p. 54/156] não ajudarmos as plantinhas que aí semeamos, a competição desenfreada as asfixiará. Com frequência, no fim do verão literalmente não restará mais nada delas, todas terão "morrido" ou, na melhor das hipóteses, alguns restos murchos continuarão a levar uma triste existência. Onde os animais vivem em colônias, densamente aglomerados, como pessoas em residências urbanas, aí aparecem os sintomas reais da carência de habitação [Wohnungsnot]. Na ilha de Laysan, no Pacífico, Schauinsland2 teve ampla oportunidade de observar os locais de nidificação das aves marítimas, onde os direitos do proprietário foram reforçados com uma consistência brutal. As [aves] recém-chegadas ocupavam os melhores lugares e seus jovens prosperavam de maneira magnífica. Já as [aves] retardatárias tiveram de se contentar com os piores locais de morada. É aqui que se vê o maior número de fiIhotes de aves degradados, com plumagem desgrenhada e pernas feridas, marcadas pela água salobra; é aqui que predomina as maiores taxas de mortalidade infantil e centenas de cadáveres ficam no entorno. Ele se sentia realmente impelido a comparar a vida dessas aves com as relações humanas.

Os mesmos processos ocorrem quando existe um rápido fluxo e dispersão em consequência da exploração de uma nova área, talvez de um continente inteiro, pela qual, em poucos séculos, o aspecto biogeográfico de uma ampla área é transformado, tal como um canteiro de jardim ou uma falésia o é em poucos meses. Desde o início do século XVI, a América tem experimentado uma europeização de seu mundo animal, vegetal e de povos, de tal modo que em alguns lugares levou a uma completa reversão das relações. No que diz respeito ao mundo dos povos, não é necessário gastar nenhuma palavra diante dos 80 milhões de europeus e africanos na América do Norte, com os quais se depararam poucas centenas de milhares de índios em decadência, compelidos às áreas mais desfavoráveis. [p.55/157] É sabido que já no século passado os pampas, os Ihanos e as pradarias estavam repletos de cavalos e gado de ascendência europeia. A América não é recoberta apenas por plantas cultivadas de origem estrangeira, mas também por imigrantes que se difundiram por si próprios. Até mesmo no sudoeste dos países andinos a macieira europeia se fez de tal modo familiar3 a ponto de co-determinar a impressão da paisagem. E assim como os negros na Jamaica se tornaram nativos onde tribos caraíbas es${ }^{2}$ Hugo Hermann Schauinsland (1857 - 1937), um zoólogo alemão. [N.T.I.]

3"Heimlich", adjetivo que remete a "Heim" (lar, casa) e "Heimat(-land)" (terra natal, pátria). [N.T.] 
tavam assentadas, lá o mangusto cinza (Herpestesgriseus) introduzido para exterminar as cobras proliferou descontroladamente de maneira prejudicial.

É claro que não podemos admitir que toda espécie imigrante possa fincar raízes apenas pelo fato de suplantar imediatamente uma [espécie] nativa. Em grandes áreas há sempre, também, uma grande seleção de espaços de vida [Lebensräumen]. No solo, na água, no ar e nas diferentes altitudes e profundidades desses elementos existe espaço para todos os mais distintos organismos vivos, cujas áreas de difusão como que se recobrem mutuamente, na medida em que assumem um único e mesmo espaço. Após a descoberta da América, plantas e animais da Europa foram aí introduzidos, dispersando-se sem que suplantassem em todos os casos os [animais e plantas] nativos. Não se pode dizer, por exemplo, que os cavalos tornados selvagens tenham suplantado o bisão das pradarias do interior da América do Norte. Isso foi feito muito mais pelo ser humano, que o tirou [das pradarias] com pólvora e bala na caça. Do mesmo modo, ao lado dos bois e cavalos tornados selvagens dos pampas permaneceu um espaço para os avestruzes sul-americanos4.Até mesmo o coelho, apesar de ter se tornado uma praga local, encontrou locais de morada [Wohnplätze] mesmo nas dunas de areia da Austrália, onde não precisou desalojar nenhum animal nativo. Em todos esses casos, portanto, estratificam-se, por assim dizer, entre e sobre novas e antigas áreas de morada [Wohngebiete]. Desse modo, a história da colonização na América também nos mostra o modo como os [p. 56/158] espanhóis logo se estabeleceram em suas cidades no solo ocupado antes deles pelos índios, e de onde eles governavam, convertiam e exploravam os índios deixados na tranquila posse de suas terras, enquanto os colonos germânicos e franceses na América do Norte logo expropriavam os nativos daquele lugar da terra da qual viviam por meio da caça e da agricultura; uma luta aniquiladora foi a consequência, cujo prêmio pela vitória era constituído pelo espaço, pelo solo. Os índios foram a parte derrotada; eles tinham no solo apenas uma breve permanência.

Mas na vida dos povos vemos também povos inferiormente posicionados vencerem povos superiormente posicionados, quando eles têm uma melhor permanência no solo. É certo que os beligerantes e agressivos mongóis e manchus conquistaram a China, mas entraram em declínio frente à densa população e assumiram seus costumes. A mesma imagem temos em todas as

4Por "avestruzes sul-americanos", no original alemão, Ratzel supostamente quis designar as "emas". [N.T.I.] fundações de Estado dos povos nômades, em especial também nos Estados conquistadores [Erobererstaaten] 5 germânicos do sul da Europa na [época] da Völkerwanderung6. Inúmeras formas animais e vegetais inferiores apenas permaneceram vivas graças a esta mesma força. Nessa luta por espaço [Kampf um Raum] trata-se não apenas do espaço de morada [Wohnraum], onde a planta se enraíza e a ave se aninha. Está em questão muito mais o espaço de alimentação [Ernährungsraum], que é muito maior do que o espaço de morada [Wohnraum]. Quando nossas montanhas ainda ofereciam espaços suficientes de abrigo aos predadores, o urso e o lince já estavam em processo de extinção, porque suas áreas de alimentação se estreitavam mais ano a ano. Não apenas a agricultura, a agricultura alpina e a silvicultura tornaram litigiosas suas áreas, mas sim o ser humano, enquanto caçador, entrou em competição com eles, e quanto mais exíguo se tornava o ganho de suas áreas de predação [Raubgebiete], mais incisiva ficava a disputa que eles preparavam pra si. A árvore sozinha manter-se-ia e desenvolver-se-ia por um longo tempo em espaço estreito, mas se ao seu redor [p. 57/159] crescessem, mais rapidamente, árvores cuja sombra lhe cobrisse, seu espaço de vida lhe seria estreitado e ela morreria. Talvez a proteção imediata contra a queda de rochas e avalanches Ihe seria retirada, e com isso a segurança de seu espaço de vida [Lebensraum] seria diminuída. Mas as ervas da floresta que prosperam em sua sombra morrem tão logo que uma fresta na floresta permita que mais luz a penetre e seu desaparecimento precede ao daquela [árvore].

Também onde se fizeram sentir a restrição e a contenção mecânicas do espaço de morada e de alimentação - que se pode perseguir tão bem na história do bisão americano -o estreitamento do espaço se realizou de fato e de certo modo selou, a partir do distanciamento, o destino dos animais que emigraram aparentemente de maneira voluntária. 0 íbex dos Alpes, o muflão da Córsega e o alce dos países bálticos orientais não esperavam até que fossem expulsos, recuando frente ao ser humano assim que experimentaram sua periculosidade; eles não apenas o evitavam, como também evitavam sua proximidade, a qual thes estreitava seu espaço de livre movimentação [freien Bewegungsraum]. Que existam tais relações também entre um animal e outro, pode-se

\footnotetext{
${ }^{5} \mathrm{~A}$ formulação de Ratzel dos "Estados Conquistadores" se refere às tribos germânicas que invadiram o sul da Europa. [N.T.]

"'Völkerwanderung", literalmente "migração dos povos", é a expressão germânica empregada para designar as "migrações bárbaras", "invasões bárbaras" ou "período das migrações" de vários povos, mas sobretudo de povos germânicos, desde a Europa Central rumo a todas as direções do continente, ocorridas entre cerca de 375 d.C. e 568 d.C. [N.T.]
} 
chegar a esta conclusão a partir da posição [Lage] e da forma [Gestalt] de algumas áreas de difusão [Verbreitungsgebiete]; as áreas de nosso coelho comum e a do coelho da neve seriam inteiramente assim, como se este tivesse recuado frente àquele.

Mas em muitos casos isso que se chama recuo nada mais é do que a extinção de uma espécie sobre um solo, que é então imediatamente ocupado por outra [espécie], como se esta tivesse esperado pela ampliação de seu espaço de vida [Lebensraum]. Bem conhecido é o "recuo" de uma determinada planta frente à invasão de outra. Que o abeto no norte da Alemanha esteja enterrado em pântanos, em cujas margens ainda encontramos apenas florestas de faia fechadas, sugere um processo como esse. E, aliás, sabemos, a partir do conteúdo dos sambaquis [p.58/160], que também o tetraz-grande migrou com o abeto. Nesse sentido, também as áreas das famílias de flora e fauna do Ártico e Alpes separadas por um amplo espaço-entre-si [Zwischenraum] são áreas de recuo, ou talvez ainda mais as pequenas ilhotas da sequoia-gigante, cujos restos se conhece a partir de uma série de lugares de achados terciários, também do Alasca e Disco7, e que hoje estão restritos a poucos recortes completamente pequenos de vales e vertentes individuais do oeste da Sierra Nevada da Califórnia. Supõe-se que tais organismos vivos tenham "recuado" de suas amplas áreas de morada [Wohngebiete] para os estreitos locais de morada [Wohnplätze] de hoje; na realidade, contudo, são os últimos escombros e restos de suas outrora enormes áreas.

As manifestações de degeneração [Verkümmerungserscheinungen] nos povos forçados a recuar foram tão frequentemente descritas, que não necessitam mais nenhuma repetição. Em parte, elas reconduzem nitidamente ao estreitamento do espaço de vida [Lebensraum], o qual não basta mais para a vida de caçador, pescador e pastor, por onde se configuram a desintegração social, o declínio econômico e as consequências da pobreza e da fome. A baixa estatura de alguns povos marginais que moram nas fronteiras do ecúmeno climaticamente desfavoráveis, pobres em alimentos e afastadas das trocas (sul-africanos, australianos, terra-foguenses, norte-asiáticos, entre outros) poderia estar relacionada com esse fato. Virchow8 acreditou ter encontrado, na comparação dos lapões 9 com os povos pigmeus africanos, efeitos

${ }^{7} \mathrm{Não}$ está claro qual dos muitos lugares chamados Disco Ratzel tem em mente. [N.T.I]

${ }^{8}$ Rudolf Ludwig Carl Virchow (1821-1902), médico, antropólogo, patologista, arqueólogo, biólogo, escritor, editor, e político alemão. [N.T.I.]

${ }^{9}$ Atualmente designado de "sami". [N.T.] físicos [decorrentes] da escassez nos dois casos. De maneira muito mais evidente, animais e plantas manifestam fenômenos análogos. As camurças dos Alpes ainda podem aparecer para nós como animais numerosos, mas já foram impelidas para as altas altitudes, onde não encontram mais o espaço e o alimento como outrora nas áreas de difusão maiores e climaticamente mais favoráveis; ao contrário, a camurça bosniana, cujas áreas de morada [Wohngebiete] ainda não estão tão apinhadas, abarcando também grande floresta, quase no nível do mar junto a Travnik [p. 59/161], é provavelmente por isso um animal mais forte, o que se manifesta especialmente na "formação de chifres". A única região da Europa central onde ainda existem veados, cujo tamanho e força nos dão a impressão de um eco do tempo dos veados gigantes, são as florestas originárias da confluência do rio Drau [com o Danúbio] na Croácia, em especial as florestas originárias de junco, atravessadas por caniçais e pantanais; alces com galhadas de $11,5 \mathrm{~kg}$ não são aí nenhuma raridade. Falando acerca deste "cervo primitivo da atualidade" [Urhirschen der Jeztzeit], A. von Mojsisovics10 enfatiza justamente "o pasto rico e diversificado, a característica do terreno que se estende por milhas", portanto, sobretudo as relações espaciais [Raumverhältnisse] vantajosas. Mas se nos recordarmos de que aqueles cedros gigantes da Califórnia estão entre as mais altas e mais poderosamente desenvolvidas árvores da Terra, não poderíamos mesmo reconhecer o atrofiamento como uma consequência inevitável da limitação de espaço, mas sim, ao contrário, enfatizar a alta probabilidade de que processos da vida são dissolvidos, em diferentes sentidos, através do recuo e da perda de espaço. Existem organismos vivos flexíveis que se adaptam a condições piores, e [organismos vivos] inflexíveis que, frente s mesmas condições tornam-se vítimas.

Também a consideração dos testemunhos histórico-terrestres nos conduz ao mesmo ponto, a saber, a regressão de espécies antigas e a progressão de novas. É claro que o caráter limitado do espaço de vida da Terra [Beschränktheit des Lebensraumes der Erde] torna necessário que uma espécie antiga desocupe o lugar [Platz räumt11] que uma [espécie] nova precisa para o seu desenvolvimento. Nesse sentido, nova criação e progressão pressupõem regressão e declínio. É o mesmo que a morte e o nascimento de indivíduos. Enquanto a espécie antiga desocupa seu lugar em lenta regressão, a nova preenche suas lacunas igualmente de maneira paulati-

\footnotetext{
${ }^{10}$ Johann August Georg Edmund Mojsisovics de Mojsvar (1839-1907), a geólogo e paleontólogo austro-húngaro. [N.T.I.]

11"Platz räumen
} 
na, passo a passo. A experiência ensina que em alguns casos isso certamente é um [processo de] recuar e avançar. Desse modo, poderia ser mesmo válida a concepção [p.60/162] de que a espécie antiga em geral recua, porque seu espaço é ocupado. A história da extinção dos povos da natureza [Naturvölker] com o avanço dos povos de cultura [Kulturvölker] fornece algumas provas disso. E, de fato, esta resposta teria vindo cedo, permanecendo ainda em aberto a questão do quanto de perda de espaço da espécie antiga se dá por razões internas que residem na decadência geral de sua força vital [Lebenskraft], e quanto se dá pelo avanço vitorioso da espécie nova. Em outras palavras: é possível provar a perda de espaço como causa do desaparecimento de milhões de formas de vida que povoaram sucessivamente a Terra? Neste próprio processo esta [perda] desempenha o papel principal; isso nos ensinam os acontecimentos, cujas testemunhas somos nós. Historicamente, nenhuma espécie e nenhuma raça foram extintas de maneira repentina sobre um amplo espaço, mas sim o recuo em espaços cada vez mais estreitos sendo em todo caso a expressão exterior do refluxo. Comumente se tratava também de espaços com piores condições de vida [Lebensbedingungen].

Mas não conhecemos um único acontecimento exterior na história da Terra, ao qual pudéssemos remontar essa extinção de maneira simples. A hipótese, de simplicidade aparentemente formidável, segundo a qual no final de cada época geológica a vida inteira da flora e da fauna de até então teria sido destruída pelo fogo ou pela água, tem se mostrado infundada. Ela falhou, pela primeira vez, na fronteira entre a era terciária e o presente. Ninguém pode afirmar que todos os animais e plantas que deixaram seus restos em uma das formações terciárias, tenham desaparecido no final desse período. Pelo contrário. Quando passamos dos depósitos terciários mais antigos para os mais recentes, o número de restos de animais e plantas que ainda hoje vivem na Terra cresce continuamente. No médio terciário temos de 10 a 40 por cento e no alto terciário de 40 a 90 por cento das espécies que ainda hoje existem. Não há, portanto, em geral, nenhuma fronteira nítida entre a era terciária e a nossa. [p. 61/163] Deste modo, representantes existentes foram preservados até o presente, todavia, a partir de formações ainda mais antigas. E, rigorosamente ao lado disso, grandes famílias foram então novamente extintas, as quais tinham cunhado com sua estampa a vida de uma época.

É curioso o fato de que o grupo dos braquiópodes, ao qual está associado o mais antigo organismo vivo reconhecível de maneira precisa, a Linguella, proveniente do baixo Cambriano, tenha sobrevivido até o presente com poucas modificações. Lingula e Discina são gêneros que foram preservados daqueles tempos primitivos até 0 presente. Até mesmo suas espécies variaram tão pouco que se pode observar apenas uma suave diferença entre algumas paleozoicas e as ainda hoje existentes. Espécies de bivalves se mantiveram até o presente com poucas alterações, tanto as dos grupos de esfíncter semelhante, quanto as de esfíncter distinto. Do grupo dos cefalópodes, a nautilidae, que tinha se desdobrado em aproximadamente 1800 espécies no Siluriano, continua viva apenas com o gênero nautilus, que existe desde a formação jurássica. Mesmo os vestígios mais antigos de animais domésticos não estão tão distantes dos nossos escorpiões, milípedes e grilos. Temos caracóis terrestres que existem desde o período carbonífero. E, desse modo, grupos inteiros de organismos vivos continuam a viver felizmente sem ter feito qualquer progresso em sua organização. Se examinarmos os restos dos animais mais inferiores que chegaram até nós, as conchas calcárias e fósseis dos foraminíferos, as conchas e esqueletos silicosos dos radiolários, encontraremos, portanto, nas formações mais antigas as mesmas formas ou formas similares que as encontradas no presente. Como muitas diferentes formas podem ter aparecido também no decorrer do desenvolvimento geológico, desaparecendo em seguida, o ápice do desenvolvimento desses grupos não foi ultrapassado desde o período siluriano. Também as esponjas silicosas já ocorrem [p. 62/164] em formas altamente desenvolvidas, não-enraizantes e, por isso mesmo, superiores. Mas, ao lado disso, os grapitólitos existentes de maneira escassa no cambriano, abundantemente desenvolvido no siluriano, precariamente representado no devoniano, foram extintos sem legar nenhum parente. Desse modo, não sabemos em qual grupo do reino animal temos de colocá-los. Os cistídeos, que pertencem aos equinodermos, passaram por um desenvolvimento similar. Eles surgiram no cambriano e desapareceram no carbonífero. Os trilobitas, que devem ter se ramificado de outros grupos de crustáceos antigos em épocas pré-cabrianas remotas, tiveram no período cambriano seu desenvolvimento superior, foram ricamente representados no siluriano e desapareceram após terem se tornado raros já na formação carbonífera.

Um dos grandes enigmas no desenvolvimento da vida na Terra é a extinção de alguns dos maiores e mais antigos grupos de animais no limiar do terciário. Os 
répteis que dominaram a terra e o mar nos períodos do triássico, jurássico e cretáceo, foram extintos no mais antigo terciário. No oceano, os grandes mamíferos, especialmente as baleias, tomaram o seu lugar; em terra, o fizeram os mamíferos e as aves. Os répteis ou pterodáctilos voadores desapareceram do ar. Os amonóides e belemnites primitivos, outrora abundante e ricamente desenvolvidos, foram reduzidos a poucos retardatários que legaram seus restos no terciário inferior. Vários grupos de caracóis e bivalves, que até então eram em parte onipresentes também desapareceram. Dentre eles estão os curiosos bivalves de casca grossa conhecidos como rudistas. Também os primitivos braquiópodes declinaram rapidamente. Com essas modificações, a fauna marinha tornou-se completamente diferente, começando a virar aquilo que hoje nos rodeia.

Algumas razões podem ser consideradas como prováveis [p. 63/165] e possíveis para essa extinção, mas nem mesmo todas as razões explicam integralmente o fato. Quando os répteis terrestres e aéreos desaparecem, isso pode estar relacionado ao aumento dos mamíferos e pássaros que tinham uma vantagem decisiva por sua organização mais completa. Grandes répteis marinhos podem ter ficado ameaçados frente a mamíferos marinhos em parte ainda maiores, tal como a baleia de sangue quente. Os peixes ósseos darão uma contribuição considerável ao desaparecimento tão notável de numerosos grupos de moluscos, em especial dos amonóides e belemnides. Se, ao lado disso, restam certamente também razões internas poderosas que residem na própria organização, pode-se, assim, persistir em nossa consideração de que um grupo animal substitui outro espacialmente e que, com muita frequência, ocorre uma diminuição numérica antes da extinção, que deve significar uma diminuição da difusão, isto é, da permanência no solo. Além disso, especialmente nesse caso as interações de todos os grupos e formas de vida são importantes em nossa Terra. Nenhum [grupo e forma de vida] existe de maneira independente em relação a outro, nenhum pode ser pensado e entendido apenas para si. E é no vir-a-ser e no transcorrer das formas de vida que tais interações ganham validade. Quem poderia negar a possibilidade de que organismos vivos microscópicos, dos quais todos os vestígios foram apagados, pudessem tornar-se atuantes na extinção das maiores famílias de plantas e animais, do mesmo modo como eles aniquilam as plantações de antigas culturas vegetais em solo empobrecido?

\section{A BORDA FRONTEIRIÇA [Grenzsaum]}

Na luta por espaço sempre surge uma oposição entre interior e exterior, entre o núcleo da área e as áreas marginais [Randgebieten] ou áreas fronteiriças [Grenzgebieten]. Também nesse caso essas fronteiras [Grenzen] não podem ser concebidas como linhas divisórias, mas sim como bordas [Säume] [p. 64/166], pois apenas sob o pressuposto de que elas são espacialmente divididas, seja de forma vinculante, seja separada de forma insular ou estendida, compreende-se sua situação [Stellung] como campos de luta [Kampfplätze] estabelecidos naturalmente no vaivém dos deslocamentos espaciais dos organismos vivos. Afinal, por causa da composição particular de sua flora, fauna, de seus habitantes humanos, as bordas fronteiriças [Grenzsäume] estão, em muitos casos, explicitamente separadas das áreas nucleares [Kerngebiete]. Isto fica especialmente visível em espaços menores, onde não raro a borda fronteiriça [Grenzsaum], enquanto uma área de características completamente especiais, circunda o núcleo.

Os estrangeiros [Fremdlinge] que percorrem amplas extensões e que são adaptáveis, penetram, partindo do exterior, nas áreas de fronteira [Grenzgebiete] das ilhas e avançam tão longe quanto as condições naturais permitem. Assim, nas ilhas do Oceano Índico, as palmeiras e os pandanus formam uma extensa borda [Saum] de vegetação litorânea densa, atrás da qual aparecem apenas as formas vegetais particulares. A própria borda é de aspecto muito mais parecido de ilha para ilha do que em relação à vegetação do interior da ilha. Ilhas muito pequeninas, como a ilha Redonda, junto à ilha Maurício, e [outras] similares, estão inteiramente cobertas por essa [vegetação]. Em Socotra também as partes médias e mais altas do interior são o lar da flora nativa. Isso lembra o modo como, desde o princípio, os negros imigrantes tomaram completamente o solo nas menores ilhas das Antilhas, e [lembra] ainda mais as bordas costeiras [Küstensäume] de cultura europeia dentro de todas as áreas coloniais não-europeias, tanto na China quanto na Oceania ou na África ocidental e mesmo no Levante.

Nas altas montanhas, vemos os habitantes de planalto se esforçando para subir as encostas dos cumes insulares, e não poucos dentre eles se misturam até mesmo com a flora das ilhas de neve e de gelo dos Alpes. Na flora nival da Suiça, Heer 12 designa, dentre 150 espécies que possuem em comum com a flora ártica,

${ }^{12}$ Oswald Heer ou Oswald von Heer (1809-1883), geólogo e naturalista suíço. [N.T.I.] 
28 plantas de planaltos também existentes nas planícies que os entremeiam. [p. 65/167] Em vastas áreas que foram tomadas pela cultura nas montanhas, esses migrantes deslocaram os vegetais alpinos de elevadas altitudes. Curiosamente, nenhuma dessas plantas sobe até a região nival, e também não ocorreria no Ártico: um sinal de sua força vital [Lebenskraft] e capacidade de adaptação e, ao mesmo tempo, um curioso análogo com a ampla difusão [Verbreitung] de muitos habitantes costeiros.

Em todos os três reinos da vida, a permanência da vida no solo fica mais fraca nas áreas de fronteira [Grenzgebieten]. Redução rápida e extinção precoce são o destino de plantas, animais e povos que habitam as fronteiras do ecúmeno. Os povos marginais do Hemisfério Sul, na África do Sul, Tasmânia, Austrália, Nova Zelândia, Terra do Fogo e em muitas ilhas oceânicas, apresentam o mesmo definhamento e morte lenta que os povos árticos da Eurásia e da América do Norte. Ao lado disso, a extinção dos pássaros gigantes das ilhas do oceano Índico e do Pacífico e no [Hemisfério] Norte a extinção da vaca-marinha-de-Steller, da alca, da baleia-da-Groenlândia, o declínio ameaçador do urso marinho e, em muitos lugares, da morsa. As áreas fronteiriças da vida nas montanhas apresentam a mesma imagem. 0 ibex, o muflão, o abutre-barbudo, o pinus cembra, o cedro-do-líbano são apenas alguns exemplos notáveis. Já em 1870, Friedrich Simony 13 lamentou que até mesmo no planalto de Dachstein a escavação de raízes tivesse dizimado a mestiça e a genciana. A valeriana alpina e o edelvaisse foram efetivamente destruídos em muitas partes dos Alpes.

Esse declínio nas áreas fronteiriças [Grenzgebieten] não está finalizado com a extinção de uma forma de vida em uma ilha ou em um grupo de montanhas; com isso, a fronteira é apenas deslocada, e o mesmo processo começa agora em lugares que estão postados mais próximos ao ponto central da área de difusão [Verbreitungsgebiet]. Com a penetração dos franceses no Canadá e na Nova Escócia [p. 66/168] e dos ingleses na Virgínia teve início o refluxo dos índios norte-americanos na margem oriental mais externa de sua área de difusão, avançando vagarosamente por todo o continente, como um órgão ou portador de todas as influências que foram perniciosas a esse pequenino povo [Völkerschen]. 0 refluxo do bisão, do alce, do cervo canadense e de outros animais avança de maneira semelhante. A fronteira permaneceu

${ }^{13}$ Friedrich Simony (1813-1896), geógrafo austríaco e pesquisador alpino. [N.T.I.] de maneira duradoura como a área onde se encontravam os pontos mais fracos desses seres humanos e animais e onde, portanto, o ataque podia ser realizado de maneira mais exitosa.

Mas por que a fronteira das áreas de difusão é tão fraca? Talvez as áreas de difusão dos povos sirvam melhor à explicação dessa questão. Os lapões, os samoiedos, os iacutos, os tungúsicos, e os chuckchis, [povos] que ocupam a fronteira do ecúmeno na Eurásia, tiveram que se dispersar amplamente para poder prolongar sua vida nessas regiões inóspitas, sendo obrigados a mudar ininterruptamente seus locais de morada [Wohnplätze] para acompanhar a rápida flutuação das condições de vida. Eis porque são pequenos os pequeninos povos [Völkerchen] nômades, desde o princípio fracos em número e em permanência. 0 clima árido e a vegetação esparsa da sede de sua morada [Wohnsitze] admitem a criação de gado apenas em escala limitada. Especialmente aí reside a oposição entre eles e seus parentes da Ásia central, porquanto lhes falta o suporte de grandes rebanhos. A rena é apenas um substituto escasso. Acrescenta-se agora o fato de que o clima e a escassez provocam doenças apenas mesmo neles, diminuindo sua expectativa de vida, assim, estão dados, de maneira suficiente, pontos de ataques que devem enfraquecer a situação [Stellung] dos povos nas áreas de fronteira do ecúmeno.

A posição [Lage] na fronteira onde dois povos se chocam não é tão desfavorável. Destarte, também aqui há [p. 67/169] razões evidentes de fraqueza. Nas relações primordiais, tais povos interpunham entre si um espaço mais amplo possível, deixando-o vazio a fim de não se tocarem diretamente. Então, outros povos se amontoavam nesse espaço e ameaçavam as sedes de morada [Wohnsitze] de ambos colocando-se de maneira menos densa em direção ao espaço vazio. Ou quando o espaço na Terra também havia se tornado tão apertado para os povos que eles começaram a se apinhar, empurrando, conjunta e confusamente, as sedes de suas moradas [Wohnsitze] para ambos os lados das áreas de fronteira e dando origem a áreas de fronteira mistas, que são, para todos os povos que nelas habitam, áreas de fraqueza. É fácil para um povo perder as áreas de morada periféricas ilhadas por estrangeiros ao seu redor, como exclaves de suas áreas encerradas. Basta recordar das áreas de fronteira germano-eslava, germano-húngara e germano-italiana. 


\section{O ESPAÇO AMPLO ATUA PRESERVANDO A VIDA}

Aproximamo-nos agora de uma faceta da questão espacial da vida [Raumfrage des Lebens] que até aqui quase não foi contemplada; e acreditamos, de fato, que ela irá se mostrar importante do ponto de vista biogeográfico e, em especial, do ponto de vista antropogeográfico. Nas obras de História lemos certa vez, de maneira oportuna, a seguinte expressão: "a marcha de Napoleão rumo à Rússia fracassou na amplitude do espaço do reino russo"; e em livros estratégicos 14 não passa despercebido o significado de um espaço amplo que pode proteger um [povo] agredido e arruinar o agressor. Mas no espaço amplo reside algo muito maior, eu poderia dizer, algo criativo. No desenvolvimento da vida, cada ampliação da área de uma raça ou espécie significa primeiramente seu crescimento em número, em seguida, sua adaptação às mais diversas condições de vida e, por fım, a diminuição da possibilidade de regressão à raça-tronco ou espécie-tronco [p. 68/170] através de cruzamento. Não se pode esquecer, com isso, o fato geográfico elementar de que, se um espaço cresce ao quadrado, sua periferia aumenta apenas em progressão aritmética; isso significa, em outras palavras: quanto maior o espaço de uma forma de vida, menor a possibilidade de contato e cruzamento com seus vizinhos.

Tomemos um exemplo a partir do mundo vegetal. 0 cembro (Pinus cembra) pertence àquelas árvores que outrora estavam difundidas sobre uma grande parte da Eurásia. Atualmente, ele ainda existe em grande extensão apenas no norte da Ásia, enquanto em nossas montanhas ele recuou amplamente. Suas localizações e até mesmo exemplares podem ser contabilizados, por exemplo, nos Alpes bávaros. Ele se manteve em conjunto, portanto, apenas na parte espacialmente mais ampla de sua área; e, além disso, recobre ainda uma região ampla de maneira dispersa, que em si mesma é muito diversificada, e também nela reside a garantia de sua duração. Para poder viver sob condições climáticas tão diversas, tais como as predominantes entre o mar de Okhotsk e os Alpes ocidentais, o cembro deve ter se difundido originalmente por espaços muito amplos, provavelmente ainda mais amplos do que hoje durante um período de resfriamento. Isso the conferiu a vantagem da adaptação versátil e, ao mesmo tempo, o peso das massas de um organismo vivo que está difundido por milhões de quilômetros quadrados. Mas uma terceira vantagem que tem ainda muito mais peso é a proteção dessa espécie

${ }^{14}$ Ratzel se refere aqui à livros de estratégia militar. [N.T.] de pinheiros, quando estava ainda na origem, contra cruzamentos com formas congêneres. Essa proteção Ihe foi oferecida justamente pelo tamanho de sua área de difusão [Verbreitungsgebiet]. Uma variedade que está determinada a tornar-se com o tempo uma espécie bem diferenciada, apenas alcançará esse objetivo no caso da mais rigorosa especialização [Absonderung], que impeça o cruzamento com a espécie-tronco e a regressão em suas propriedades, ou caso ela se disperse tão rapidamente que o espaço [p. 69/171] por ela recoberto atue como proteção, na medida em que sua ampliação encurte a fronteira de contato com outras formas. Mas também essa dispersão pressupôs, em muitos casos, o surgimento em um lugar restrito no "ponto central da criação". Milhares de outras plantas e animais das altas montanhas possuem uma história da difusão como a do cembro. Também a edelvais, que está próxima da extinção em nosso país, continua a crescer como uma planta de pasto amplamente difundida no sul da Sibéria.

Talvez a questão do espaço da área de origem seja, atualmente, a mais candente da antropogeografia. Em geral, apenas agora os biogeógrafos [Pflanzen- und Thiergeographen] têm prestado um pouco de atenção às singularidades da origem das espécies e subespécies e, em especial, naquelas [singularidades] que tangem o espaço. Mas para a raça loira, para os arianos, semitas, uralo-altaicos, bantus e outras raças ou famílias de povos, trata-se de admitir localidades completamente determinadas como áreas de origem ou mesmo de explicá-las como prováveis. Para a raça loira, até mesmo paisagens que medem alguns milhares de quilômetros quadrados foram caracterizadas como área de origem. Somos então da opinião de que não apenas não precisamos permanecer absolutamente em suposições, mas sim podemos prosseguir se nos respaldarmos no significado justamente desenvolvido de espaço associado à formação e preservação de novas raças, subespécies ou espécies. A fim de não deixar surgir influências estranhas no tempo extremamente longo que foi necessário à formação e fixação da raça loira, podemos supor ou uma ilha enquanto região de origem ou uma área de terra firme muito grande. Mas nada depõe a favor de uma ilha, [enquanto] tudo [depõe] a favor de uma ampla terra firme de origem.

De uma raça tão nitidamente diferenciada o espaço exige sobretudo o lento devir. À plenitude do tempo deve corresponder a amplitude do espaço. Um povo não permanece [p. 70/172] assentado por gerações no mesmo solo, devendo dispersar-se porque cresce. 0 tipo de 
crescimento não faz aí nenhuma diferença: se um povo cresce sem ser molestado, ele flui lentamente por toda a periferia em seus arredores. Se ele cresce sob tempestades e atritos internos, então partes dele são empurradas pra fora, enquanto outras se retiram por si para áreas afastadas. Em ambos os casos, o espaço do povo cresce com o tempo necessário para efetuar no povo a passagem para uma nova subespécie ou raça. Portanto, refutamos como improváveis, de antemão, hipóteses acerca da origem das maiores raças ou grupos de povos a partir de áreas estreitas.

Mas no caso dos arianos, as ramificações do grande tronco linguístico atuantes de maneira embrionária e de tipo complexo - tronco linguístico este que certamente foi muito mais poderoso outrora do que hoje -, requerem o espaço para uma divergência livre. Se a árvore precisa de luz e ar para crescer, essa árvore de línguas e povos precisou de solo livre para se ramificar. Apenas em amplos espaços cada ramo pôde conservar para si uma autonomia tão grande, de modo que pôde desdobrar as especificidades que então lhe garantiram sua existência única. A estabilidade das características raciais exatamente nos habitantes das regiões ao redor do mar Báltico foi tão frequentemente admirada, porque aí, dentro dos túmulos neolíticos, existiam esqueletos idênticos àqueles existentes nos [túmulos] da idade do Bronze e do Ferro, sendo os crânios idênticos aos existentes nos túmulos de outrora. Isso não é, tal como se tentou interpretar, uma inércia de milhares de anos que vai contra todas as leis da vida dos povos; ao contrário, significa algo diferente e maior: protegido na parte marítima contra influências raciais mutáveis, rodeado por parentes raciais na terra, nada racialmente estrangeiro fluía aos povos das regiões ocidentais do mar Báltico e em especial da península escandinava. Mas o que aqui [p. 71/173] dissemos sobre arianos e loiros europeus supõe certamente que em seu mais amplo entorno se formem raças misturadas e assim, de fato, ao sul dos loiros ficam as áreas dos arianos de cabelo escuro e pele morena clara, e mais adiante seguem os grandes espaços dos povos semitas e hamitas, nos quais o sangue negro misturado mostra-se cada vez mais evidente através de traços mulatos; do mesmo modo acontece no oriente, as formas transitórias que ocorrem já em uma grande parte da Europa do Leste estando relacionadas com os mongóis. Os lapões, que até hoje ocupam a fronteira humana no norte da Europa, não poderiam ser aí nenhum fenômeno antigo. Ao contrário, não é improvável que em seu período de formação os loiros também no norte tivessem as costas livres. A raça loira, portanto, não teria surgido, mas sim se preservado nas regiões bálticas. Tratar-se-ia talvez de uma confusão da área de preservação [Erhaltungsgebiet] com a área de origem [Ursprungsgebiet] na teoria da origem báltica ou escandinava da origem dos loiros? Para responder essa questão examinemos agora, por fim, quais relações espaciais em geral aparecem junto ao desenvolvimento de novas formas de vida.

\section{OS FENÔMENOS ESPACIAIS NO DESENVOLVIMENTO DE NOVAS FORMAS DE VIDA}

O aspecto espacial da formação de uma raça ou espécie deve ser pensado em três seções distintas de dimensões muito divergentes. Em primeiro lugar, uma mutação de espécie [Abartung] surgirá em uma área específica, na qual ela ainda existe rigorosamente ao lado do espaço que a espécie-tronco ocupa, ou é até mesmo abarcada por ele. Se a nova forma se mostrar viável, ela irá se dispersar, e essa nova área que é rodeada por uma área de borda ou de fronteira, na qual ocorrem formas transitórias ou híbridas, será maior do que [p. 72/174] a primeira e a ela estará ligada. As áreas de fronteira vão desaparecer com o tempo, à medida que suas formas transitórias são absorvidas ou se desenvolvem em raça ou espécie própria, e então a área da nova espécie estará em contato com áreas onde habitam espécies amplamente divergentes. Mas agora essas [espécies] se alastram, talvez de sua parte, na primeira área, destruindo sua conexão. Por fim, apenas algumas ilhas ou exclaves da área outrora grande e coerente ainda permanecem. Se contemplarmos essa marcha veremos uma área de origem estreita desde os primórdios seguida por uma área grande conectada com passagens, depois uma área unitária ampla sem passagens e, por fim, novamente áreas de refluxo estreitas. Mas não nos esqueçamos que se trata aqui de processos que precisam de milhares de anos para se realizar.

Em muitos casos, o desenvolvimento de novos organismos vivos vai se apoiar, portanto, em uma sequência de retração e expansão espaciais. Novas subespécies e espécies vão exigir em muitos casos espaço estreito para se isolar; mas quando elas adquirem suas novas características, elas precisam então estabelecer em espaço amplo a força de resistência contra cruzamento e influências climáticas. Exatamente a preservação das espécies em suas propriedades especiais é mesmo muito mais notável do que sua origem por meio de varia- 
ção conhecida; e esta preservação existe graças precisamente ao fechamento do campo contra cruzamentos desfavoráveis, podendo vencê-las apenas por meio de rápida dispersão, quando a própria natureza não colocou limites, como no caso das ilhas. Com isso as variações mais suaves são aniquiladas; a mais viável, mais dispersável, recobre uma área mais ampla possível; com isso, formas intermediárias caem fora; diferenças nítidas postam-se lado a lado; luta e progressão são acelerados: cresce aquilo que se poderia chamar de gradiente de vida [Lebensgefäll]. [p. 73/175]

Consideremos agora o estágio final no desenvolvimento de raças e espécies, aquele da dissolução da área de morada [Wohngebiet] no interior de uma porção de áreas de preservação [Erhaltungsgebiete]. Todas as raças e espécies em refluxo nos dão a mesma imagem: áreas estreitas, separadas umas das outras de maneira ampla, sem nenhuma ligação através de espécies com vínculo próximo de parentesco, nenhuma gradação, mas sim lacunas; espécies com vínculo de parentesco jamais ocupam essas áreas separadas, mas sim gêneros semeIhantes que possuem um desenvolvimento inteiramente diferente, anterior a si. Formas limitadas e intermediárias desapareceram. Se atravessarmos a faixa tropical do Velho Mundo de oeste a leste, encontraremos o macaco gorila antropoide nas regiões em torno do golfo da Guiné e certamente apenas na assim chamada Guiné-Bissau, algo em torno de $0^{\circ}$ e $5^{\circ}$ de latitude sul, adentrando mais profundamente no interior encontra-se o chimpanzé - até onde a floresta oferece espaço aos animais escaladores, portanto, até os grandes lagos africanos orientais, aproximadamente até onde alcançam a palmeira-de-dendê e o papagaio cinza; mais distante disso, para além da lacuna do oceano Índico, encontra-se o orangotango nas Grandes Ilhas de Sonda: três gêneros amplamente distintos em áreas estreitas separadas de maneira distante, cada uma habitada por uma única espécie que demonstra apenas variações supérfluas. Esse é o estado da retração desenvolvido até a ruptura, um estado insular. Essas três "ilhas de difusão" [Verbreitungsinseln] dos primatas não lembram o caráter biogeográfico de ilha genuína de abrigar gêneros monotípicos, portanto, gêneros com apenas uma espécie ou poucas espécies especialmente frequentes? Esses monotipos demostram uma especialização prosseguida por longo tempo em uma área limitada, especialização essa que conduziu à preservação, talvez também ao aprofundamento de propriedades especializantes, sem desdobramento correspondente de uma rica plenitude de espécies.

Do ponto de vista de tais ilhas de difusão, na contem- plação dos efeitos dos espaços estreitos sobre o desenvolvimento [p. 74/176] da vida, o conceito de ilha deve ser concebido mais amplamente como biogeográfico do que como legítima e habitualmente geográfico. Também chamamos de ilha uma área de vida [Lebensgebiet] restrita e bem delimitada, mesmo quando não está rodeada por água, tal como a Geografia requer. Um oásis no deserto, um cume de montanha de clima e estrutura rochosa particulares, uma bacia lagunar profunda gelada, uma caverna: tudo isso são ilhas de difusão da vida. Mesmo uma fenda úmida no meio das montanhas reúne seu pequeno mundo especial de plantas e animais sob condições, que divergem ligeiramente do entorno. E uma fonte na qual uma espécie de verme ainda não encontrada em nenhum lugar, o Phreatothrix Pragensis, leva sua existência pacífica, já é por isso uma área de vida particular para si. Que não se trate com isso de incidentes esporádicos, apenas mostra também a riqueza das cavernas em espécies animais, as quais pertencem exclusivamente a elas. Nas cavernas húngaras e nas do Planalto Cársico existem 68 espécies de besouros especiais; se adicionarmos aí o famoso proteidae, rico em subespécies locais, o caracol de caverna proveniente do gênero especial Zospeum, 20 aranhas, 4 centopeias, vários crustáceos, várias espécies de Orthopteroidea, apenas a partir dessas cavernas restritas mesmo em sua totalidade, tanto a da Carníola15 quanto a do Planalto Cársico, emerge diante de nosso olhar um mundo vivo [Lebewelt] inteiramente único. Os oásis existem como ilhas nas quais a vida se amontoou dentro dos desertos pobres em vida. Ascherson 16 contabilizou no assim chamado oásis do deserto líbio 232 espermatófitas enquanto o Saara inteiro conta com no máximo 700 espécies. Contudo, o Saara compreende 6 milhões de quilômetros quadrados, já o Pequeno Oásis compreende 138 quilômetros quadrados!

Assim como as ilhas estão rodeadas pelo mar, as partes mais altas das montanhas são como ilhas montanhosas por meio das faixas climáticas que seguem uma sobre a outra, encerradas pela planície. Através disso, os maciços individuais tornam as áreas de vida [Lebensgebiete] muito separadas, em espaço estreito, [p. 75/177] que se comportam em muitas relações como ilhas. No Kilimanjaro, acima da flora de estepe, que alcança até 1.700 metros, existe uma faixa de floresta úmida tropical; raramente ambas são separadas por uma fina vegetação de samambaias. A faixa florestal tem em média 1.200 metros de largura. Acima, temos superfície de

\footnotetext{
${ }^{15}$ Região da Eslovênia. [N. T.]

${ }^{16}$ Paul Friedrich August Ascherson (1834-1913), botânico alemão. [N.T.I.]
} 
grama e ilhas de arbustos e, a 4.700 metros, as últimas espermatófitas.

Existem mesmo espécies que ocorrem desde o planalto até as altitudes de grandes montanhas de 3.000 metros com propriedades inteiramente concordantes, mas mais frequentes são os exemplos de espécies que ocorrem de maneira sobreposta em diferentes zonas de altitude, de modo que uma área de difusão é rodeada por outra de forma concêntrica. Assim encontramos as três brilhantes borboletas de Apollo dos Alpes: Parnassius Apollo, delius e mnemosyne, nessa ordem, nas regiões alpinas mais baixas, mais altas e a mais alta.

Além disso, também as montanhas repartem grandes regiões [Länder] em pequenas por meio de suas ramificações. Os Alpes não apenas formam um mundo para si com um rico mundo vivo [Lebewelt], que conta, na zona de alta montanha, mais de 400 espécies especiais e com as formas árticas em torno de 700 espécies vegetais; eles também se colocam ao mesmo tempo entre duas floras, que não são menos tão distintas entre si, porque existe essa barreira entre elas.

Não apenas o clima medeia a especialização das regiões montanhosas mais altas; a falta de estatura da floresta cria lá condições de vida em delimitação insular, as quais são encontradas novamente apenas em amplas regiões de estepe, e também para isso indicam mesmo os parentescos da camurça e da marmota, entre outros. Lembra a dispersão dos quirguizes, cuja área genuína é a estepe, sobre as pastagens montanhosas dos Pamir. Talvez se possa incluir aí até mesmo os camelídeos, que habitam estepes do Velho Mundo e planaltos andinos de caráter estépico do Novo Mundo. [p. 76/178]

Tanto o zoólogo quanto o botânico que colecionam [espécies] conhecem as ilhas rochosas, nas quais se amontoam plantas "calcícolas" ou "calcífugas". Assim que cruzamos suas fronteiras, que pisamos em outros solos novos, elas ficam de fora. A fronteira rochosa estabelece um corte frequentemente de maneira nítida, tal como aquele entre o mar e a terra. Nos Alpes, pode-se frequentemente reconhecer na fronteira do pinheiral a abrangência do solo granítico ou gnáissico, os pinheiros aparecendo com o solo cálcico. Dentre os animais, os caracóis terrestres são os mais destacados adeptos do cálcio; a limitada área cálcica do jurássico no leste da Transilvânia possui apenas 16 espécies do gênero existentes somente aí: o Alopia. Esses caracóis Alopia se agarram, sob o sol mais quente, nas rochas calcárias, das quais eles no máximo esfregam vagarosamente pequenos líquens, seu alimento.

Em ambos os hemisférios, as colônias de habitantes de áreas polares, que reaparecem em altitudes e depressões da zona temperada, pertencem aos espaços de vida [Lebensräume] estreitos mais notáveis. Assim como nas altas montanhas do norte da Eurásia e da América do Norte reaparecem indivíduos da fauna e da flora de Spitsbergen, Groenlândia e de outras regiões árticas, também encontramos nas profundezas da bacia gelada do oceano Atlântico indivíduos da fauna do norte do Mar Ártico. Em ambos os casos, essas ilhas polares nas zonas temperadas contêm, ao lado dos verdadeiros colonos árticos, espécies próprias que são frequentemente semelhantes àqueles, mas que às vezes são também de grande peculiaridade, verdadeiramente ilhados. Com base na depressão marinha da área gelada do oceano Atlântico, Sars17 detectou dentre 102 crustáceos, 53 espécies árticas e 42 espécies únicas, ou seja, 41 por cento.

Os lagos relictuais pertencem também aos espaços de vida [Lebensräume] encolhidos e fragmentados. Como se sabe, essa expressão foi empregada pela primeira vez por Leuckart18. Mais tarde ela [p.77/179] ficou um pouco em descrédito, porque muitos habitantes dos lagos, que foram concebidos como relictos de faunas marinhas mais antigas e mais dispersas, não puderam ser indicados como tais. Mas as espécies de mysis19 dos lagos sueco e russo, também do mar Cáspio, que são afins às do mar gelado do norte, outros crustáceos de semelhante difusão, o cão marinho cáspio (Phoca caspica), que é afim ao do ártico, fornecem mesmo provas cabais do caráter de relictos marinhos. Exatamente essas relações estreitas tornam prováveis as conexões cáspio-ártico de idade não elevada, ainda que até agora os geólogos russos não tenham podido demonstrar depósitos marinhos a elas associadas, nem de um lado, nem de outro do Ural. Entretanto, o mais interessante lago de relictos é, certamente, o Tanganica, que compreende não apenas um mundo animal destacadamente marinho, mas sim também, provavelmente, muito antigo, que indica uma conexão marítima há muito retraída.

$\mathrm{Na}$ maioria dos casos, essas ilhas de difusão serão os restos de regiões maiores, que outrora eram concatenadas; mas não é possível conceber simplesmente o desmembramento de uma área de difusão como marco etário; Sem dúvida a fragmentação do lugar de morada dos índios na América do Norte é o sinal de seu recuo pela raça branca, que é a mais recente na região [Land].

\footnotetext{
${ }^{17}$ Provavelmente George Ossian Sars (1837-1927), um biólogo marinho e de água doce norueguês. A área em questão é o cume Wyville Thomson. [N.T.I.]

${ }^{18}$ Provavelmente Rudolf Leuckart (1822-1898), um geólogo alemão. [N.T.I.]

${ }^{19}$ Gênero de crustáceos. [N.T.]
} 
Mas a ocorrência dos caraíbas na América Central não poderia ser concebida da mesma maneira; eles também vivem em pequenos grupos e, de fato, viviam outrora ainda mais dispersos, mas não em consequência de recuo, e sim como imigrantes. Eles são os mais recentes na região comparados com seu entorno densamente habitado. A mesma imagem de difusão nos é apresentada pela colonização, seja ela de natureza vegetal, animal ou humana: nos primórdios são dispersas e com o tempo vão se adensando. A diferença entre ilhas de [p. 78/180] difusão recuada e de difusão progressiva não pode ser encontrada no núcleo das áreas, mas em sua posição em relação à outra e na qualidade de suas condições de vida. As áreas dos que recuam encontram-se rompidas, são irregulares, desvantajosas, enquanto as áreas dos que avançam buscam os melhores lugares, encadeiam-se e buscam crescer um em direção ao outro. $\mathrm{Na}$ discussão sobre as diferentes idades dos elementos da flora britânica, exatamente essa discontinuous distribution foi validada pelos biogeógrafos ingleses como marco etário do assim chamado elemento lusitano. 0 grande número de animais e plantas são comuns na Irlanda, no sudoeste da Inglaterra, no oeste da França ou no sudoeste da França, na Espanha, em Portugal, em parte já reconhecido por Edward Forbes, a quem remonta também a expressão "elementos lusitanos", dando de fato a impressão de ter ocupado outrora uma área mais ampla, que se fragmentou e encolheu com a perda de terra e com as mudanças climáticas. Mas quando G. $\mathrm{H}$. Carpenter20 derivou daí o princípio geral de que as espécies britânicas mais difundidas estão atreladas a um ramo mais jovem ou mais novo do mundo animal dessas ilhas, enquanto localmente restritas, R. F. Scharff observou com inteira razão na sua "History of the European Fauna" que, se também áreas de difusão desmembradas têm idade antiga - o que também não admitiríamos após o afirmado acima -, áreas grandes e concatenadas não deveriam estar atreladas sempre a espécies jovens. Por outro lado, do ponto de vista das áreas de difusão incompletas e em transformação permanente, pode-se chegar à conclusão acerca de uma perigosa lógica da ausência de uma forma de vida dentro de uma determinada área, a saber, de que ela nunca tenha existido aí, portanto, de que ela deva ter vindo de um lado completamente diferente. Se a Rana arvalis se estende da Sibéria até a Alemanha central, mas inexiste no sudeste, sul e oeste da Europa, pode-se vê-la como um dos muitos [p. 79/181] migrantes para o oeste europeu, que provêm da

${ }^{20}$ George Herbert Carpenter (1865-1939), naturalista e entomologista britânico. [N.T.I.]
Sibéria. Mas se certas cicindelas e certos carabídeos da Europa são atribuídos apenas por isso à origem norte-asiática, por que não os encontramos na Espanha, na Madeira, nas Canárias, onde eles deveriam mesmo ocorrer, caso tivessem surgido na Europa, na Ásia ocidental ou na África do Norte? Essa conclusão não é, portanto, obrigatória. Pois por que eles não deveriam, da mesma forma que milhares de espécies, ter desaparecido no sul e sobrevivido no norte? Nós queremos apenas aguardar se um dia não encontraremos seus restos nas camadas do terciário tardio ou pós-terciário, exatamente ali onde hoje hesitamos em estabelecer sua origem.

\section{CENTRO DE CRIAÇÃO OU ÁREA DE PRESERVAÇÃO?}

Quando examinamos o conceito de centro de criação [Schöpfungszentrum] em suas propriedades geográficas, frequentemente não encontramos nada além do que a parte central de uma área de difusão maior, na qual uma forma de vida ocorre de maneira a mais abundante e a mais rica possível. Se essa espécie, raça, etc. tenha se originado nela, é uma questão cuja dificuldade muitos não fazem ideia, a tal ponto que usam a palavra centro-de-criação de maneira muito leviana. No empenho de responder a esta questão, raramente, ou talvez até mesmo nunca, chegaremos com certeza à área de origem. No entanto, com muita frequência chegaremos à área de preservação mais pura de uma forma de vida. Quem nos dá o direito de designar a Austrália, tal como é inteiramente comum, o centro de criação dos monotremados e marsupiais? Apesar de não ter sido criada na Austrália, a fauna de monotremados e marsupiais está ali preservada. Indivíduos podem ali ter surgido, mas vemos uma antiga difusão desses grupos animais sobre uma parte maior da Terra em todos os estratos da era terciária e em restos fósseis dispersos ainda mais antigos. A Austrália é apenas sua [p. 80/182] área de refúgio e de preservação. Claro que há também casos onde podemos dizer de uma espécie ou subespécie: aqui ela surgiu, aqui é seu centro de criação. Mas os destinos dos organismos vivos são tão dependentes das transformações da superfície terrestre, que este [centro de criação] só é possível sempre onde a origem não data de há muito ou onde se trata de uma espécie adaptada localmente de maneira completa. Posso aceitar certas subespécies de hieracium terem surgido na região dos Sudetos e subespécies de salgueiro nórdico em Nova Zembla, e isso até mesmo com bastante certeza desde o fim da era glacial. Desse modo, também posso dizer da solitária saxifraga do 
Chimborazo, uma das mais altas plantas vasculares, que é peculiar a essa montanha: o Chimborazo é o seu mais provável centro de criação. Muito provavelmente é ele também que deu origem ao proteidae cego na estreita área de caverna da Carníola, onde ele ocorre apenas em sete especializações locais; mas se a notável aranha de caverna Eschatocephalus gracilipes ocorre em cavernas da Carníola e da Morávia, a questão do centro de criação torna-se imediatamente irrespondível; ela poderia ter surgido então até mesmo num terceiro grupo de cavernas existente entre ambos, que há muito está soterrada. Mais distante, posso dizer, do ponto de vista da própria especialização que os imigrantes europeus experimentam na América do Norte: a América do Norte parece tornar-se o centro de criação de uma nova sub-raça do homem europeu. Mas está descartado que também a Austrália exerce influência formativa de tipo totalmente similar sobre as crianças da Europa? Desse modo, não posso dizer do coelho da neve que as regiões árticas são seu centro de criação; mas ele poderia também ter surgido mais ao sul, onde ele ainda hoje existe nos Alpes e em outras altas montanhas, em uma época em que o clima ártico dominava a América do Norte e a Europa nórdica. [p. 81/183] Isso não é absolutamente improvável. Então, sua suposta área de criação ártica seria, portanto, apenas sua maior área de preservação. Mas na mesma posição [Lage] desse mamífero estão incontáveis plantas e animais das altas montanhas. Não menos do que 150 espécies da flora nival dos Alpes suíços também ocorrem no Ártico; 134 delas estão em consonância com as escandinavas, $68 \mathrm{com}$ aquelas da América Ártica e, dessas 68, 41 ocorrem de novo nas montanhas da América do Norte; 94 espécies ártico-alpinas existem também no Altai e 24 estão em casa no Himalaia. Em outras partes da Terra repete-se essa renovação de organismos vivos das zonas mais frias para as zonas de altitude correspondente em direção às montanhas localizadas junto à linha do Equador. Assim, enquanto o caráter sul-africano predomina mesmo no Kilimanjaro acima de $2.800 \mathrm{~m}$ na zona de prados montanhosos, ao contrário, na zona florestal predomina o parentesco abissínio, até mesmo com relações singulares para com as montanhas camaronesas. Nas montanhas da Ásia Central está difundida uma série de animais alpinos ao mesmo tempo com espécies do norte da Sibéria e dos Urais ou é representada em formas de parentesco próximo. Em todos esses casos, seria mesmo claramente imprudente aceitar simplesmente os Alpes ou quaisquer outras montanhas como centro de criação [Schöpfungszentrum], caso nenhuma outra razão pudesse ser aduzida como consonância ou parentesco próximo das espécies.

Frequentemente, as mesmas plantas ou animais que habitam isoladamente nas montanhas, vivem dentro de algum distanciamento mesmo na planície. 0 exemplo do pinheiro é instrutivo nesse sentido, mas talvez seja ainda mais o do tetraonidae ou tetraz-grande. Na Galícia ele é peculiar às planícies; nas montanhas medianas alemãs e nos Alpes apenas ele é peculiar às montanhas e, na maioria das vezes, certamente em posições muito remotas e escondidas. Na Boêmia, o galo-lira ainda alcança eventualmente a várzea; nos Alpes ele ultrapassa até mesmo a fronteira florestal no período de cortejo nupcial. [p. 82/184] Assim, nossa edelvais, mesmo nos altos Alpes, vive cada vez mais recuada, como planta campestre do sul da Sibéria até o sul da Ásia Central e Cachemira.

Aves migratórias do Ártico estabelecem estadia de passagem em nossas montanhas, embora formas do extremo norte tais como o borrelho-ruivo (eudromias morinellus) escolham pântanos e lagos de altitude posicionados a mais de $2.000 \mathrm{~m}$ e caráter climático polar. Isso mostra como ilhas de difusão podem ter ressurgido nas montanhas.

Devem haver outras razões na difusão geográfica atual ou mais antiga que nos impelem a aceitar uma área inteiramente determinada como área de origem, mas que também, por sua vez, não pode então ser circunscrita muito rigorosamente. Temos nos Alpes uma porção de plantas que pertence aos mais característicos habitantes das altas montanhas. Elas não possuem relações com o Ártico e com as planícies circundantes; portanto, ou elas surgiram nos Alpes ou migraram de outras montanhas tão cedo que elas puderam se adaptar e se formar como espécies únicas. A essas pertencem as prímulas, soldanellas, androsace, achilea, saxifragas, phyteuma, gentianas, campanulas, valerianas. Dentre elas a maioria se difundiu agora também nas montanhas da Ásia Central. Muitos gêneros estão representados lá com numerosos semelhantes, enquanto em nossas altas montanhas eles ocorrem apenas com uma ou duas espécies. A prímula não está representada de maneira tão pobre em nossa terra, mas ela é mesmo muito mais rica ainda nas montanhas da Ásia Central. Também a África conta com prímulas dentre suas plantas de altas montanhas. A Abissínia tem uma subespécie de primula verticillata, duas outras ocorrem no Sinai e na Arábia. Os parentes mais próximos, P. Aucheri e floribunda, conhecemos de Mascate e do Himalaia ocidental. Uma forma um pouco mais distante existe no Himalaia oriental. Há, portanto, um aumento partindo do sul [p. 83/185] e do 
leste. Se agora o desenvolvimento mais rico das prímulas tem seu lugar nas montanhas da Ásia Central, esse parece ser um caso onde nós reconhecemos com alguma clareza o caminho no qual uma dispersão para o sul e para o leste se realizou. Poderemos a partir daí afirmar também, com probabilidade, que as montanhas da Ásia Central sejam a área de origem do abundante gênero das prímulas alpinas. Uma única irradiação não teria sido suficiente, mas a repetição da mesma a partir da área semelhante em diferentes direções nos faz mais confiantes.

Apenas a riqueza em prímulas das montanhas centro-asiáticas também não poderia ocasionar o translado da origem para aquela região. Exatamente essa frequência deve nos alertar quanto a tirarmos conclusões muito rapidamente sobre a área de origem; nisso reside uma grande fonte de equívocos. A Achatinella teria tido sua origem nas ilhas do Havaí, porque lá não só cada vale, mas cada segmento de vale tem a sua própria forma? Poderíamos também nos lembrar de quando Christ21 atribuiu origem alpina a 41 espécies vegetais alpinas, porque elas ocorrem mais frequentemente nos Alpes do que no Norte; já Heer validou, com toda razão, que a ocorrência mais ou menos frequente não poderia decidir acerca do lar original, pois a experiência mostra que até mesmo muitas espécies de plantas e animais se desenvolveram de maneira mais exuberante em novas localidades do que no lar [original]. De maneira semeIhante, tentamos transladar a origem de um povo para a área de sua mais ampla e mais espessa difusão, comparada com as colônias europeias no exterior, cujo número de seres humanos em parte ultrapassa já agora amplamente o da mãe-pátria.

O que é decisivo para a eleição de uma provável área de origem, neste caso das prímulas, pode também ser em todos os outros casos: o rastreamento de uma [p. 84/186] dispersão até um lugar onde, partindo de qualquer um dos lados, convirja para uma segunda ou terceira área. Assim, obtemos de qualquer maneira uma área de irradiação [Ausstrahlungsgebiet]; embora permaneça ainda em aberto a questão se ela seria a primeira. A razão da predileção do Ártico como "centro de criação" de numerosas plantas e animais holárticos reside claramente em sua situação correspondente para a dispersão das plantas ártico-alpinas. Não se pode negar que muitos feixes convirjam no Ártico. Diz-se com razão: o mundo vivo ártico seria o resultado da aglomeração de uma vida, que tinha se originado no sul e daí migrou rumo

${ }^{21}$ Konrad Hermann Heinrich Christ (1833-1933), botânico suíço especializado em samambaias. [N.T.I.] aos polos, assim deveríamos encontrar diferenças muito maiores nela e também as floras e faunas singulares das altas montanhas seriam muito mais distintas das árticas. A grande concordância fala a favor da preponderância da área de disseminação [Ausstreuungsgebiet] ártica. Mas isso toca apenas a dispersão, não a origem: o mesmo velho equívoco. Mas se nós aceitarmos que isso havia também em altas montanhas em períodos mais antigos da História da Terra, e que, por necessidade, existiram em sua altitude faunas e floras de altas montanhas, assim a conexão entre estas e as áreas circumpolares climaticamente semelhantes existiram já anteriormente e teve de conduzir para a troca de suas formas de vida, especialmente porque em épocas de climas mais frios suas áreas se expandiam para todos os lados, aproximando-as umas das outras. Os achados de restos vegetais e animais ártico-alpinos provam mesmo até onde foram essas dispersões e aproximações.

Houve uma época, da qual ninguém duvida, que a origem da flora das altas montanhas dos Alpes e de outras altas montanhas da Europa apenas poderia ser encontrada no Ártico. Oswald Heer emprestou a essa teoria uma expressão clássica em vários trabalhos, de maneira mais decisiva ainda em seu póstumo [p. 85/187] "Flora Nival da Suiça" [Flora Nivalis der Schweiz]. É muito notável que antigamente ninguém tenha lançado a questão de por que então as montanhas glaciais não puderam ter tido a mesma força de fazer surgir plantas de hábito ártico-alpino. Heer demonstrou de fato que das 150 espécies de plantas ártico-alpinas, 94 também ocorrem no Altai e 24 ainda no Himalaia, mas ele não levanta a questão mais evidente, a saber, se o Altai poderia ter gerado várias daquelas que migraram daqui rumo ao norte e ao oeste. Os Cárpatos possuem 82 delas; por que também os Cárpatos não deveriam ter ensejado algumas delas?

Não apenas ao Ártico, mas sim a toda a zona circumpolar do hemisfério norte até a zona temperada adentro, devemos remontar, portanto, a origem de tais formas nórdicas, que existem na região holártica inteira, mesmo quando apenas de maneira insular. Eu poderia ainda recordar o tetraonidae, nosso tetraz-grande, nosso galo-preto, nossa galinha-do-mato que, do mesmo modo, formam um anel de difusão em torno de todo o norte de nosso hemisfério, mas estão completamente ausentes no sul da Ásia e no sul da América do Norte e quase completamente ausentes nas regiões mediterrânicas. A lagopus ou galinha-da-neve está representada com apenas espécies únicas na Groenlândia, na América do Norte ártica, na Escandinávia e nos Alpes, então na Escócia, no norte da Ásia e nas Ilhas Aleutas, no noroeste 
da América do Norte, em Spitsbergen. 0 gênero lyrurus está difundido com uma espécie desde os Pirineus até o Oceano Pacífico e com uma [espécie] bem limitada no Cáucaso. 0 tetrao e seus parentes estão difundidos pelo norte da Europa, norte da Ásia e América do Norte. 0 tetrastes ocorre como galinha-do-mato desde o norte da Espanha até Sacalina, e duas outras espécies habitam o norte da Rússia e a China. Não se trata aqui de nenhum centro de criação, mas sim de uma série inteira de áreas de origem e áreas de preservação, aparentadas através de posição e natureza.

[p. 86/188] Agora ficará claro que nossa tarefa não pode ser a determinação de um ponto central ideal para uma área de difusão sempre coincidente mesmo em seu atual tamanho e extensão; apenas a posição e a forma da área inteira devemos e podemos determinar. A aceitação amplamente difundida "A área de origem de uma espécie coincide em geral com o ponto central de sua difusão geográfica" (Scharff, History of the European Fauna, 1898) é uma pressuposição inteiramente infundada do ponto de vista geográfico22. Partindo de uma premissa tão inadmissível seguiria que o lar [original] do cervo residiria na Ásia Central, o que não encontra nenhum apoio em outros fatos. Se hoje encontramos na Ásia não apenas os camelídeos, mas também seus restos diluviais nas bordas da Europa, na região do Ponto23, muito mais provável torna-se para nós a sua origem asiática. Em muitos outros casos, também a origem asiática nos é provável; se a área de difusão compreende uma parte grande da Ásia, ao contrário, ela libera grandes partes da Europa, em especial da Europa ocidental e do sul. Mas não contabilizaríamos aí, por exemplo, um caso como o do [gênero] bombina ausente das ilhas britânicas, mediterrânicas e da Escandinávia, mas que ocorre na Europa do Leste e Central e no leste da Ásia, porque a existência de espécies em ilhas e penínsulas é sempre mais flutuante do que em grandes áreas continentais.

Portanto, investigações desse tipo são necessárias não nos pontos centrais, mas sim nas periferias. $E$ isso vale para todas as questões biogeográficas acerca da origem. Apenas o [ponto] final atual de um movimento de dispersão sempre estará tão próximo de nós, que nós o veremos claramente; isso é, por conseguinte, justamente a área que a raça, a variedade, a espécie, ocupa hoje. Determinar seu tamanho e posição com precisão é sempre a tarefa principal. Além dessa constatação, podemos no máximo [p. 87/189] perceber ainda a direção

${ }^{22}$ Scharff, A História da Fauna Europeia, 250. [N.T.I.]

${ }^{23}$ Nome histórico da região meridional do mar Negro, na atual Turquia. [N.T.] na qual a área se desenvolveu nos últimos tempos. E, por fim, somos capazes de criar talvez ainda uma suposição sobre a proveniência remota a partir do prolongamento da direção para trás, mas que sempre será hipotética. Isso é o extremo. Buscar por um ponto central pode, com isso, apenas nos confundir de maneira evidente. Especialmente na investigação da origem de um povo ou de uma raça, não se pode esquecer que não se deve perguntar nem por pontos (origem) nem por linhas (caminhos), mas sim por espaços [Räume] ou áreas [Gebiete]. 